\title{
Supporting Young Children's Communication with Adult Relatives Across Time Zones
}

\author{
René Vutborg, Jesper Kjeldskov, Jeni Paay \\ Department of Computer Science, \\ Aalborg University, Denmark \\ rene@vutborg.dk, \{jesper, jeni\}@cs.aau.dk
}

\author{
Sonja Pedell, Frank Vetere \\ Department of Information Systems \\ The University of Melbourne, Australia \\ \{pedells, f.vetere\}@unimelb.edu.au
}

\begin{abstract}
Regular contact between children and their adult relatives can be a problem if they live in different time zones. In this situation, finding an agreed time to contact each other can be both confusing and complicated. This paper presents a study of the effect of time zone differences on communication between grandparents and grandchildren living in different time zones. We deployed a system between time zone distributed families to study this effect and analysed its use based on four parameters of time and events based theory: rigid sequential structures (that some events cannot occur before others), fixed durations (that most events always last the same time), standard temporal locations (that events have a standard time when they occur during the day) and uniform rates of recurrence (that some events always reoccur at a uniform rate). Our findings highlight the importance of: the need to consider the parents' role in facilitating contact and making the technology easy to use by children independently; the advantage of concurrent synchronous and asynchronous interaction forms; and the need to respect people's private time. These findings can inform the design of technology for supporting young children's communications with adult relatives across time zones.
\end{abstract}

\section{Author Keywords}

Intergenerational play; Play across distance; Storytelling; Communication across time zones.

\section{ACM Classification Keywords}

H5.m. Information interfaces and presentation (e.g., HCI): Miscellaneous.

\section{INTRODUCTION}

Communication over distance between children and their adult relatives is complicated when a family has to adapt to being in different time zones. There are a variety of reasons why families become distributed across time zones. One reason is migration. An adult son or daughter might move to a new country, eventually settling permanently with a husband/wife and children. This results in children growing up without easy regular physical contact with his/her grandparents, if at all. If this move includes significant geographical distance in an east-west direction, different circadian rhythms are

Permission to make digital or hard copies of all or part of this work for personal or classroom use is granted without fee provided that copies are not made or distributed for profit or commercial advantage and that copies bear this notice and the full citation on the first page. To copy otherwise, to republish, to post on servers or to redistribute to lists, requires prior specific permission and/or a fee.

OZCHI '11, Nov 28 - Dec 2, 2011, Canberra, Australia

Copyright (C) 2011 ACM 978-1-4503-1090-1/11/11... \$10.00 introduced between the two families; for example, one might be eight hours ahead of the other. Another reason that time zone differences might be introduced between children and other family members is if the parents get divorced, and one parent moves to another time zone without the child. Similarly, time zone differences can occur on a temporary basis whenever one parent travels, for example, on a business trip. Whatever the reason, it might be hard to find an appropriate time of day that suits both households, as their daily schedules can be misaligned due to time zone differences. Even though children can generally tell time by the age of six (Freidman \& Laycock, 1989), it is unclear how they cope with understanding time zone differences. This paper explores such challenges of communication between children and adult relatives across time zones by deploying a system for families with children in one time zone and adult relatives in another. We study how this system supports communication between family members separated by both distance and time zones.

In this paper we start by motivating our study with related work, followed by findings from interviews with time zone distributed families in respect to their use of our prototype system. We then describe modifications made to the system to ease the impact of time zone differences as a direct result of those findings. Outcomes from studying use of the modified system then inform a discussion on how time zone differences influenced communication between the children and their adult relatives. We conclude with consequences of these findings on designing technology for communication between children and adult relatives across time zones.

\section{RELATED WORK}

There have been some interesting investigations into the relationship between time and people. Sociologist Eviatar Zerubavel (1982) describes the emergence of the international standardization of time, and thus the concept of time zones so that people could have fixed points in time to refer to when the world was connected by railway transportation and telegraphic communication. In his book "Hidden rhythms", Zerubavel (1985) explores and dissects the concept of time. Of interest to our study, he defines four parameters concerning the concepts of time and events: rigid sequential structures (that some events cannot occur before others), fixed durations (that most events always last the same time), standard temporal locations (that events have a standard time when they occur on the day) and uniform rate of recurrence (that some events always reoccur at a uniform rate). 
Many ICT researchers have investigated the influence of different time zones on communication. Modlitba and Schmandt (2008) found that parents travelling to other time zones adjust their schedule to suit the bedtime of their children at home. Lottridge et al. (2009) found that partners living or staying in different time zones take the time difference into account when predicting the whereabouts and availability of their partner. Cao et al. (2010) conducted a thorough investigation of current practices and challenges for communication between family members across time zones and found that all families perceive the time zone difference as challenging. Interestingly, they found a trend of preferring synchronous forms of contact over asynchronous because the nature of family contact is more emotional and about catching up on daily life than functional exchange of information. Reddy and Dourish (2002) conducted a study of rhythms of activities in work, and found that the rhythms themselves provide information for users of interactive systems.

Attempts to share the daily rhythm of distributed family members or friends using technology is addressed in the work by Kim et al. (2008). They designed the BuddyClock to enable family members or friends to automatically share information about their sleeping behaviour with other people, in a close circle of friends or family. Each participant had a BuddyClock installed in his/her bedroom and had to "tell" the BuddyClock when s/he went to sleep and woke up. Other friends or family members in the same circle could then, on their own BuddyClock, see if the person was asleep or had woken up. Evaluation showed that the BuddyClock made the participants feel more connected with those who could see their sleeping pattern. One participant explicitly stated that a device such as the BuddyClock would be useful in his/her family as the mother lived 13 time zones away and always had to manually calculate if her son/daughter was awake or not.

\section{RESEARCH DESIGN}

The research presented in this paper is based on the deployment of a system integrating two existing components developed in previous research projects (Vetere et al., 2009; Vutborg et al., 2010). Before the prototype system was deployed, interviews were conducted with families to gain an understanding of how they maintain contact across time zones and challenges faced during separation. After the families had used the system, interviews were again conducted to explore how the system supported contact across time zones. During this field study, the system was modified in an attempt to better explore some of the challenges experienced by the families.

The system deployed in the field study presented in this paper can be considered a technology probe (Hutchinson et al., 2003). Technology probes are characterised by being flexible and functionally light, by incorporating data logging capabilities and by being used by researchers for understanding and provoking innovation.
As the goal of this research was to explore how time zone difference affects communication between grandchildren and adult relatives, it was important that the study involved participants who did not change time zones during the deployment period, hence lived permanently in different time zones. To accommodate this requirement, it was decided to investigate communication between grandchildren and grandparents living on different continents, ensuring that the time zone difference between them would be significant and not just, for example, one hour.

The system deployed as a technology probe comprised two previous research components that were combined for this study. Each of these components mediates communication between grandparents and grandchildren distributed in space in novel ways. Both components contain interaction forms that significantly differ from telephone conversations and webcam sessions and both components have been shown to make grandparents and grandchildren who live apart feel closer to each other (Vetere et al., 2009; Vutborg et al., 2010). Previous studies were conducted with grandparents and grandchildren who lived in the same time zone. This paper explores interactions across different time zones and the deployment of these two components allowed us to investigate interesting challenges related to familial exchanges in this specific context. We anticipate that these challenges can be generalized to time zone distributed children and parents as well.

\section{THE SYSTEM}

The system used in this study combines the "Collage" (Vetere et al., 2009) component and the "Storytelling" (Vutborg et al., 2010) component. Both were chosen for this study as they explore different types of contact between grandparents and grandchildren. Collage mediates play in both synchronous and asynchronous settings while Storytelling mediates oral storytelling in a synchronous setting only.

The two integrated components were deployed to the families using the same hardware, and thus appeared to them as one system. This was possible because the two components are very similar in interaction design. Both follow the What-You-See-Is-What-I-See approach (Stefik et al., 1987) providing a shared visual space (Kraut et al., 2002) to each of the households, through which the residents interact with the system. Interactions from one household are replicated in the other household. Primary interaction is through touch screen monitors and use of a mouse in both components. Neither component requires the use of a keyboard. Both utilise a camera phone, which the participating households can use to take photos that are subsequently placed on the shared visual space displayed in both households. Finally, both components are implemented as client-server solutions, thus enabling the two servers to share information immediately, including the personal photos taken by camera phones as they are sent to the system. 


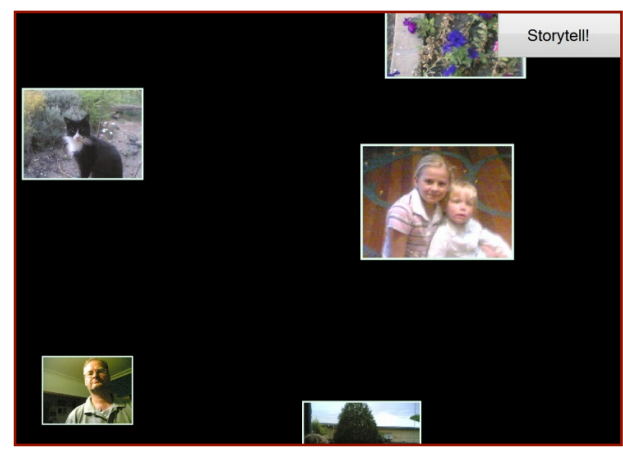

Figure 2: The Collage component. The Storytelling component is activated using the "Storytell!" button.

\section{The Collage Component}

The Collage component is built for "mediating intergenerational play" (Vetere et al., 2009) and is intended to operate continuously in the household. Personal photos appear from the top and cascade down the screen simultaneously in both households, as shown in figure 2. When a resident from one household moves a photo, this is replicated in the other household. Photos can be moved, resized and rotated. They are randomly selected to be shown cascading down the monitor, however newer photos are shown larger and more frequently than older ones. Households can send photos from designated camera phones to the system, and these are then shown immediately, accompanied by a "bling" sound to alert people that a new photo is being displayed.

Collage enables both synchronous and asynchronous interaction. One household can use the component, for example, to move photos, without the other household having their component (computer) turned on. With misaligned daily rhythms, where the families are distributed in both time and space, we anticipated that families could enjoy asynchronous possibilities such as this. Synchronous interaction is also possible with Collage. When both households have their computer turned on, they can watch the other household interact with the system, leading to playful instances, for example, "fight over control" of photos between distant family members (Vetere et al., 2009).

\section{The Storytelling component}

The Storytelling component was built to investigate how synchronous contact between grandparents and grandchildren can be improved by providing them with conversational context in the form of children's books and sharing of personal photos. When a household wishes to use the component, they must invite the other household to participate in a storytelling session. Clicking on a button labeled "Storytell!" does this. In the integrated system used in this study, this button is placed in the top right hand corner of the Collage screen (see figure 2).

When one household has sent an invitation, the other household must then actively accept the invitation. Upon agreement between the households to initiate a storytelling session, an audio channel is opened between

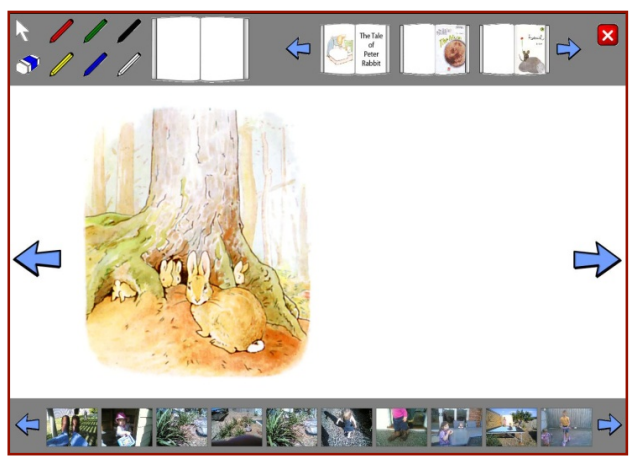

Figure 3: A storytelling session in progress showing an illustrated page from a book. The white area is the shared space. The bottom row displays the personal photos taken by camera phone. The top row displays preloaded books and coloured pencils for annotating.

the two households and the interface (illustrated in figure 3 ) is shown on the screen in both households. A set of loudspeakers and a table microphone is installed in both households to facilitate the audio channel. This combination of loudspeakers and microphones also makes it possible for multiple residents from the same household to talk simultaneously with the other household. The Storytelling component plays a telephone sound on the loudspeakers to catch people's attention when it receives an invitation to participate in a storytelling session from the other household. In a storytelling session, grandparents or grandchildren can choose to select a story (from 10 preloaded books) and subsequently tell it to the other. They can also choose to share a personal photo, taken with the household's designated camera phone, and talk about that photo. These photos can be resized and moved at will.

Finally, using a tool set of coloured pencils, they can draw on top of story pictures, personal photos or just draw on the white space. When they have used the available space, they can get a new blank "page" by pressing the large blue left- and right-pointing arrows. All of these activities, including instances of mutual grandparent-grandchildren teasing using, for example, the coloured pencils, were observed when the component was used in a previous Australian-based field study (Vutborg et al., 2010). We anticipated that families in this study might appreciate these synchronous forms of interactions in addition to the asynchronous possibilities provided by Collage.

\section{Technical implementation and integration}

The technical setup and the integration between the two components are illustrated in figure 4 . The Storytelling component is developed in C\# using Microsoft SQL Server as the database back-end, while the Collage component is developed in Flash using Flash Media Server and the MySQL database as the back-end. The only custom-made software developed for this study makes every personal photo available in both components so that householders only needed to send each photo once for it to appear in both the Collage and Storytelling components. 


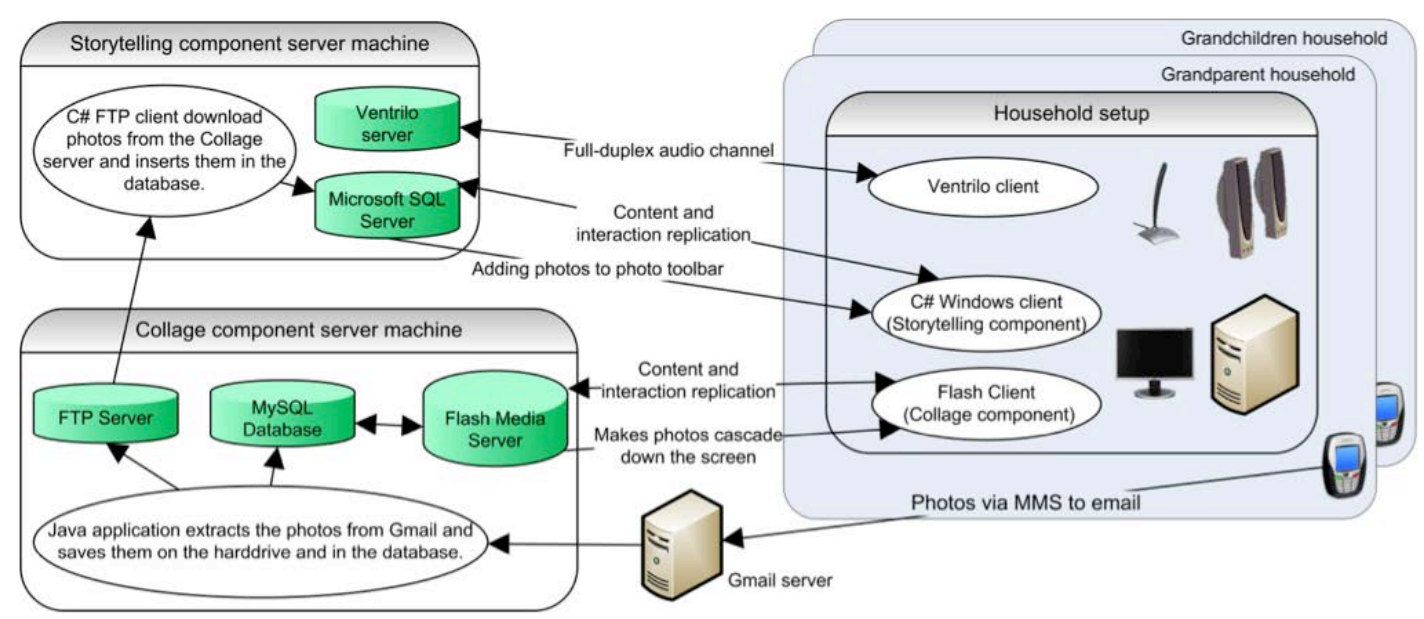

Figure 4: The technical setup of the two components, also illustrating their integration.

\section{DEPLOYMENT}

The system was deployed in a field study with two participating families. The families received no remuneration but had the costs of their involvement covered.

\section{Participants}

Participating families for the study were recruited through DENMARKhouse, a meeting place for Danes living in Melbourne, Australia. Common for many Danes visiting DENMARKhouse is that they have children in Australia while their parents live in Denmark, thus they were good candidates for the field study. The time zone difference between Denmark and Melbourne is 9 hours, disregarding Daylight Savings Time (DST). Each family selected for participation complied with a basic set of requirements. The parents had to live in the greater Melbourne area and have at least one child aged between 4 and 8 . The grandparents had to live in Denmark in their own house and not require external care. These requirements were to ensure that the family would, and could, invest the time needed to independently engage with the system and thereby generate useful data. The participating families had complete freedom regarding frequency, content and time of use. Three families volunteered to participate in the study from which the following two families were chosen. Family 1 consists of a grandfather and a stepgrandmother living in Esbjerg, Denmark. Both have fulltime day jobs. The father, mother and two children, aged 6 (boy) and 5 (girl), live in Melbourne. Family 2 consists of a grandmother living in Vejle, Denmark. She is retired and the grandfather is deceased. The father, mother and three children, aged 14 (boy), 11 (girl) and 7 (boy), live in Melbourne. Common to both families is that the grandchildren and grandparents have met physically previously in their lives, and thus have some form of relationship and knowledge of each other even though they now live in different time zones.

\section{Method}

After a family agreed to participate in the field study, set up dates were scheduled with both the grandparents in Denmark and the parents (and children) in Melbourne.
At the set up, in their homes, a semi-structured interview was conducted giving insight into the current challenges of staying in contact with their remote family members.

Following this, the system computer and the touch screen monitor were installed concurrently in the homes in both Denmark and Melbourne. To facilitate use, it was placed in a centrally located, high traffic area in the home, such as on a kitchen table. The computer and the keyboard were hidden away as much as possible. The mouse was kept visible and usable. The computer was wirelessly connected to the household's existing ADSLbased Internet connection (all households had that already). The family was informed that they could use the system in whatever way they found suitable or exciting and the different activities available in the system were demonstrated.

Every time a family used the Storytelling component, a screen capture program (CamStudio) recorded both what was shown on the touch screen and their speech. This happened automatically in the background without interfering with the use of the system. The screen shot was supplemented by a log file with time stamped entries including: every time a household tried to initiate a storytelling session; what the response was from the other household ("accept" or "deny"); and how long initiated sessions lasted. When a photo was sent to the system and therefore to both components, the sender and the time of day were logged.

When the system was collected from the households, a second semi-structured interview was conducted investigating how they used the system, what they liked and disliked about it and if, and how, the system supported communication with their remote family members.

To harvest enough data and ensure that system usage routines developed, the system was deployed in each household for three weeks. The system had to be deployed sequentially between Family 1 and Family 2 for technical reasons. The time zone difference during the deployment with Family 1 was 10 hours, because of DST in Australia, where as it was between 8 and 10 
hours during deployment with Family 2, because DST came into effect in Denmark and ended in Australia.

After the system had been deployed with Family 2 for three weeks, their use informed modifications to the system. Family 2 subsequently agreed to have this modified system installed for another three weeks. The modified system was deployed remotely to the households using remote desktop software (TeamViewer). After three weeks, the complete system was collected from them and another semi-structured interview was conducted exploring if, and how, the modifications impacted how family members used the system.

\section{Data Analysis}

All interviews were transcribed and analysed, using open coding and axial coding techniques from the grounded analysis method (Strauss \& Corbin, 1990). The outcomes were then further refined, looking for instances where the families faced issues related to one of Zerubavel's (1985) four parameters: rigid sequential structures, fixed durations, standard temporal locations and uniform rate of recurrence. We also looked for issues relating to misaligned daily rhythms in general, and were sensitive to other, non-expected issues they faced in their attempt to communicate between the households. The video recordings of all conducted storytelling sessions, $6 \frac{1}{2}$ hours in total, were also reviewed with similar objectives.

\section{FINDINGS}

\section{Challenges of Staying in Contact}

The interviews conducted with the families before the system was deployed revealed that the grandparents from both families found it difficult to really engage in conversation with their grandchildren over a regular telephone. This finding is not surprising given previous research, which confirms that children do not communicate well using telephones (Ames et al., 2010; Ballagas et al., 2009; Eviemo et al., 2004; Vutborg et al., 2010). What is interesting is that grandparents from both families had a very definite opinion that this was especially the case with boys. When asked about this, one of the grandchildren supported this by stating "I hate it, because it is a waste of time. I am always meant to talk on the phone when I am up to something - some other things". The children seldom used email to communicate with their grandparents, and when they did, they were in the background, as a parent would write the actual email.

The families also faced challenges specifically related to the time zone difference. Both families reported that the time zone difference made communication more troublesome than communication with family members living in other households in the same time zone. This was largely due to the small windows of opportunity available for communication, because, for example, one household would be sleeping while the other was at work/school. This supports the findings by Cao et al. (2010) on the difficulties of family communication across time zones. The time zone difference restricted
Family 1 to only have telephone conversations at the weekend, where both households had the time. Both families also appeared to have difficulty calculating what the time was in the remote household. When conducting the interviews, both grandparents and parents from Family 1 were well aware of what the time difference was between the two households (8,9 or 10 hours). What they continued to struggle with, however, was to remember if they were supposed to subtract or add that amount of hours to their own time to get the time in the other household. The time zone difference also seemed to make it even harder to find a common subject to talk about across time zones, as stated by one grandparent: "First you have to think: what are they doing down there? You have to think which time on the day it is".

\section{Facilitating contact by using the system}

The system successfully facilitated contact between the grandparents and grandchildren as both families enjoyed using the system and felt they were closer to their remote family members after having used the system. A grandparent from Family 1 said: "We have never had so much contact with them as now" and the grandparent from Family 2 said: "Our relationship is closer now than before". According to the father from Family 1, his daughter and his parents "hardly ever spoke on the phone [before], where now she [the daughter, aged 5] looks forward to [using] it every day pretty much". Interestingly, this outcome was reached through very different use patterns in the two families. This difference is reflected in the use statistics shown in table 1.

\begin{tabular}{|l|c|c|}
\hline & Family 1 & Family 2 \\
\hline Photos sent & 142 & 52 \\
\hline $\begin{array}{l}\text { Number of storytelling } \\
\text { sessions }\end{array}$ & 10 & 16 \\
\hline $\begin{array}{l}\text { Total duration of } \\
\text { storytelling sessions }\end{array}$ & $\begin{array}{c}2 \text { hours, } \\
36 \text { minutes }\end{array}$ & $\begin{array}{c}3 \text { hours, } \\
58 \text { minutes }\end{array}$ \\
\hline
\end{tabular}

Table 1: Statistics from three weeks use in each family.

\section{Preferring the Collage component}

It can be seen from table 1 that Family 1 clearly preferred to use the Collage component, hence non-voice contact. The grandparents had the computer turned on almost all the time when they were home, and really enjoyed watching and rearranging the photos that were flowing down in a waterfall style. The grandmother said, "every time a new [photo] arrived, we just HAD to see it". This was a regular occurrence for them, as $79 \%$ of the 142 photos taken by this family came from a member of the grandchildren household. Photos that were not recognizable would prompt talk and conversation in that household. According to the father, the grandson (aged 6) often used the Collage component, "just looking at the photos". The grandfather of Family 1 also eagerly described one episode, where he was excited to discover photos continuously coming in from the grandchildren showing them walking with their parents on Bondi Beach as part of a vacation in Sydney. This shows that the Collage component provided opportunity to follow the lives of the other household as events were unfolding. Family 1 did use the Storytelling component 
as well. A common pattern detected by analysing the video recordings was that one of the grandchildren often started a storytelling session by saying "Hej Bedstefar" (Hello grandpa), having a short conversation with the grandparent and then painting or playing with photos without talking further. Sometimes they did however speak to each other, often prompted by the parent. The photos also worked as a catalyst for conversation about daily life. Family 1 never told or used the fictional stories in the Storytelling component. The grandson (aged 6) mainly used the Collage component because, as his father said, he "is not into talking" and thus preferred non-voice contact. The opposite was the case for the granddaughter (aged 5), who mainly used the Storytelling component. She loved to talk, and actually for the first week thought that her grandfather could see her visually when she was using the storytelling component. According to the father, she "kept looking behind the screen, "Now you can't see me" and "Now you can", because they talked about the same photo so she just couldn't figure out that there wasn't a camera in there". Excluding weekends, $86 \%$ of the storytelling sessions were conducted in the morning hours for the children, often between 7 and 8 am, which was equivalent to evening for the grandparents.

\section{Preferring the Storytelling component}

Family 2 clearly preferred to use the Storytelling component, as shown in table 1 , providing voice contact between the two households. Even though the grandmother is retired, she had a busy daily schedule away from home and thus preferred the kind of intense contact with her grandchildren that the Storytelling component provided. Just playing with the photos in Collage was not enough for her. She only took a few photos with the camera phone, as she claimed, "I am not good with technical stuff". The grandchildren household took the rest of the photos within the first 11 days of the study. As they were not allowed to take the camera phone to school or to spare time activities, they found that this limited interesting scenes to capture. The family however really enjoyed the storytelling sessions. Even though this study is geared towards children under the age of 9, it was the 11-year old granddaughter who used the Storytelling component the most. She often read entire stories to the grandmother, who would listen and ask questions during the telling, both about the stories and about other matters somehow related to the stories. The stories thus worked as a catalyst for conversations between grandparents and grandchildren. The majority of oral, fictional storytelling in this family was the grandchildren telling the story to the grandmother. These storytelling sessions were always initiated in the evening hours for the children, between $5 \mathrm{pm}$ and $10 \mathrm{pm}$, which was morning time for the grandmother. When the grandmother was not available for storytelling sessions, the children used the Collage component asynchronously, playing with the photos, for example, by turning them upside down.

\section{MODIFYING THE STORYTELLING COMPONENT}

Even though both families successfully scheduled and conducted storytelling sessions, the scheduling part was found to be cumbersome as two sets of routines had to be balanced against each other with respect to both local and remote time. This was made more difficult by the apparent issues that family members had converting local time to remote time. These experiences informed modifications to the Storytelling component in an attempt to overcome this.

To make scheduling easier, an asynchronous approach was considered in the form of a direct and easy to use message channel that the families could use to schedule storytelling sessions. However this idea was not implemented because research has shown that family members across time zones "often $[\ldots]$ wait to make a [synchronous] call, rather than opting to send an asynchronous message" (Cao et al., 2010). It was thus decided that the modifications to the system should focus on improving the opportunity for unplanned, unscheduled sessions of storytelling to occur while giving the families a better understanding of the time in the other household. Two modifications were implemented to the system in an attempt to address this.

\section{Implemented Modifications}

The first modification implemented was to share an indication of availability for storytelling sessions between the two households. With the original system, the families had no way of knowing if someone from the other household was available for a storytelling session. When they clicked on the "Storytell!" button, one of two things happened. If the other household had their system turned on, they were invited to participate in a storytelling session. If their system was turned off, a message saying "Your [grandparent/grandchild] is not currently ready for storytelling" was displayed. This meant that a household resident had to press the "Storytell!" button to find out if the other household was available for a storytelling session. The parents from Family 2 reported that their children often just pressed the "Storytell!" button during the day to find out if their grandmother was available for a storytelling session. Partly prompted by this idea, and partly prompted by the way Instant Messaging clients such as MSN and Yahoo Messenger display a user's status as, for example, available or offline, an indicator showing the other household's availability for a storytelling session was implemented. To make sure that it could be seen from further away than just in front of the monitor, the indicator was implemented as a traffic light, The traffic light would be green if the other household had their system turned on, otherwise red. In some situations, showing information about another household's activities in this way could be considered an invasion of privacy, albeit an inevitable one, because if "one person in the media space [is] to have richer awareness, others must necessarily have less privacy" (Hudson \& Smith, 1996). However, since research on communication between distributed family members has found that in general privacy is something their participants "did not seem too concerned about" (Tee at el., 2009), this was not deemed a major issue here. 


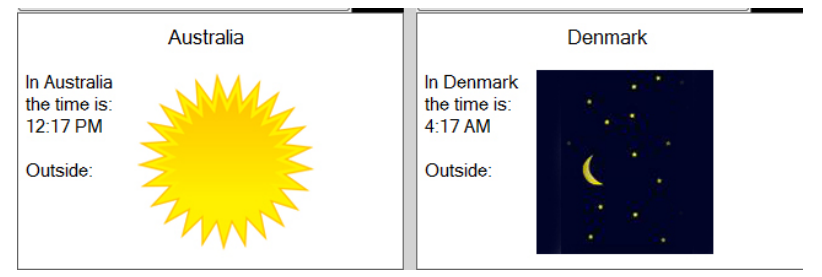

Figure 5: Illustrates modifications made to the system. The left part is shown in Denmark (grandparents), the right part in Australia (grandchildren).

The second modification implemented was an indication of what the time was in the other household at any given time. It was hoped that this would especially help the grandchildren understand when it was night and day for their grandparents. This was implemented by showing a picture of either a sun, representing daytime in the remote household, or a moon with stars, representing night-time (see figure 5). This was to ensure that the children got an indication of the time in the other household even though they possibly could not tell time yet. The time was also displayed using a digital clock with $\mathrm{AM} / \mathrm{PM}$ notation.

\section{Effects of the Modifications}

Family 2 conducted eight storytelling sessions lasting a total of two hours during the three-week period with the modified system. The indicator of availability, represented by the traffic lights, did not result in the family using the Storytelling component outside the time intervals that they used it before the modifications were put into effect. The grandmother speculates that this might be because they continued to schedule when sessions were to take place, and that sessions were always scheduled for around the same time of day. Never the less, the availability indicator was well received. The grandmother appreciated it because it showed her if the grandchildren were there or not. The mother actively used the traffic light. She kept an eye on it throughout the day and when it went green informed her children that "she's there", meaning that the grandmother had her system turned on. According to the mother, the children spent less time just hanging out around the system and this also eliminated those attempts to initiate storytelling sessions that were bound to fail because the grandmother had her computer turned off. The traffic light thus impacted the process of initiating storytelling sessions in a positive way.

The post-study interview also revealed that the children thought the sun, indicating daytime, meant the sun was actually shining in Denmark. This misinterpretation could potentially have been avoided if another photo was chosen for representing daytime. The children also told their grandmother what the weather was like in Denmark when they started a session, so the image of the sun prompted talk about Denmark between the two. The grandmother reported that the day/night photo and the digital clock did not offer any advantage to her, as she already had a good knowledge of the time zone difference.

\section{DISCUSSION}

\section{Influence of time zone differences}

The misaligned daily schedules existing between the grandparents and the grandchildren because of time zone differences affected the interaction and communication between the two households in various ways. We discuss these by relating our findings to Zerubavel's (1985) four parameters concerning the concepts of time and events: rigid sequential structures (that some events cannot occur before others), fixed durations (that most events always last the same time), standard temporal locations (that events have a standard time when they occur on the day) and uniform rate of recurrence (that some events always reoccur at a uniform rate).

\section{Rigid sequential structures}

Events and activities are often bound to happen in a specific sequential order; hence they have what Zerubavel (1985) calls a rigid sequential structure, where one event must precede another. An obvious example is that you must find a partner before you can get married. Another example is that when you are sleeping, you must wake up before you can consciously communicate with other people. Even though this might seem trivial, it presents a challenge when the context is communication across time zones. This is because in any fixed period in time, the residents of one household might be awake while the residents of another household are asleep. This was the case for the families who participated in this study as the time zone difference was between 8 and 10 hours.

\section{Fixed Durations of Sleep}

Events we engage in or activities we conduct during a day have according to Zerubavel (1985) a fixed duration, caused by either biological or technological reasons or based on conventions. The duration of a plane trip from Bangkok to Melbourne is for technological reasons fixed to close to 11 hours. When we watch a feature length movie, we expect it to last more than 10 minutes based on unwritten conventions for duration of movies. And finally because of biological reasons, we need to be asleep for approximately 8 hours a day to be well functioning in the long run in our daily life. This final point about sleep is worth stressing in this context. Even though it may appear apparent, it makes it impossible for a household to permanently cut down on their amount of sleep to decrease or even eliminate the perceived time zone difference. While making communication easier it conflicts the biologically determined fixed duration of sleep. This point is confirmed by the use patterns of the components, which show that a photo was never sent to the system, or a storytelling session conducted, when it was the middle of the night for one of the households.

\section{Standard Temporal Locations out of sync}

According to Zerubavel (1985), events and activities have a standard temporal location in the day. Lunchtime is usually around noon, dinnertime is in the evening and we usually have a standard set of hours during the day when we are at work or school, implying that children never, or only very rarely, go to school in the evening. When two households located in time zones, for 
example, 8 hours apart have to engage in shared activities, their individual perception of what constitutes standard temporal locations of these events are not affected but are, because of the time zone difference, not synchronous. The consequence of this is that at a fixed point in time, it is morning in one household and evening in the other. This affects communication between the two households. This was particularly evident in Family 1 , where the grandparents had daytime jobs and thus only had time for contact when they got home from work in the afternoon/evening, which corresponded with morning for the children. Even though the grandchildren in this family, according to the father, "love having stories told" at bedtime, they were not told a single one of the pre-loaded stories during the three weeks the system was deployed. The children might simply not even think about storytelling in the morning, in the same way it would be "almost inconceivable [...] that an event such as a dance would be scheduled for the morning" (Zerubavel, 1985). It is thus clear that the two households are significantly affected by their time zone difference while simultaneously having standard temporal locations that are not synchronous.

\section{Uniform rates of recurrence}

Zerubavel's (1985) concept of uniform rate of recurrence, describing that events and activities occur with a fairly rigid rhythmicity, is also appropriate in this context. An example of an event with a yearly rigid rhythm is Christmas, which we celebrate on the $25^{\text {th }}$ of December each year. The field study presented in this paper shows that the degree of uniformity of recurring daily events affects the type of communication that occurs. The grandparents from Family 1 were unable to modify their daily schedule to encompass synchronous activities with the grandchildren because of day-time jobs. This made the only possible window for synchronous contact the morning, before the children went to school, a period where probably neither the parents nor the children had time nor energy to participate. This factor made asynchronous contact, provided through the Collage component, more popular than synchronous contact for Family 1. Conversely, Family 2 mainly used the Storytelling component and thus engaged in synchronous contact. This was possible because the grandmother was retired and thus had the ability to adapt her daily schedule to engage in synchronous contact when it best suited the other household. This is contrary to previous findings on family communication across time zones, which found that family members typically would "not change their own schedule in order to accommodate communication with remote family, except for special occasions such as New Year" (Cao et al., 2010). In our study, the rate of recurrence of events in the life of the grandmother in Family 2 was found to be less uniform than the rate of recurrence of events, such as their work, for the grandparents in Family 1.

\section{Consequences for Design of Technology}

\section{Considering the role of the parents}

Our previous research found that parents play an important role in facilitating contact between grandparents and grandchildren living apart (Vutborg et al., 2010). This was confirmed by the activity of the parents observed in this study. One example was the parent(s) solving issues of fighting over control of the system between two grandchildren, who simultaneously wanted to use it. In this paper, we show that the time zone differences existing between the two households place their standard temporal locations out of sync. This invoked another interesting role for the parents. During the end of storytelling sessions, the parents often stepped in and scheduled a time for the next storytelling sessions with the grandparent(s). This involved a rather complicated discussion between the parent and the grandparent, involving sharing their daily schedules with each other while simultaneously calculating local and remote times in an attempt to find a time slot suitable for both households. It is doubtful if children would be able to grasp a similar organizational task, thus the parent becomes even more important for facilitation of contact between grandchildren and grandparents when time zone differences are involved.

\section{Technology being easy to use}

Parents from both families expressed that one of their favourite aspects of the system was their children's ability to use the system without parental guidance. Sometimes, children have a different sleeping pattern to their parents if they're put to sleep early in the evening, while the parents stay up late, then the children might wake up before the parents in the morning. Family 1 experienced this situation at least once, which had the system turned on 24 hours a day/7 days a week. One of their children got up very early one morning while the parents were still sleeping and initiated a storytelling session with the grandparents, who had just arrived home from work. The children also happily interacted with the Collage component without parental guidance or grandparent interaction. These examples demonstrate the advantage of designing the technology to be easy for the children to use independently. If technology is not designed in this way, the small differences in daily rhythms that may exist between parents and children in the same household can limit the children's use of the technology if the parents need to be available to initiate use or help during use. This becomes a more important issue when differences in time zones makes it meaningful for children to have contact with a distant relative at a fixed point in time when the child and the relative are awake and available but cannot be supported by the parents.

Children's use of technology in the home can however potentially be regulated by rules. One example is that the children in Family 2 were only allowed to use computers on the weekend (the parents made an exception for the system deployed in this study). Research shows that it is not unusual for parents to set up rules about their children's use of computers in the home (Rode, 2002). The ability for children to use technology single- 
handedly can thus be impacted by domestic rules set up by the parents regarding use of technology in the home. It is thus important that the designed technology either conform to these rules about technology use by children in the home or be designed in a way that increases the chance that parents feel comfortable making an exception for this particular piece of technology. This was the case in our study for Family 2, who allowed children to use this system on weekdays because it served the more important goal of increasing contact with their grandmother who lived in another time zone.

\section{Concurrent synchronous and asynchronous interaction forms}

Previous research on designing technology for use by grandparents and grandchildren living apart recommends that such technology should be designed to "encompass a diversity of interaction forms to suit the current activity level of the child" (Vutborg et al., 2010). In this paper we show that the families' patterns of use not only confirm the need for a diversity of interactional forms but are also motivated by the need to suit the activity level of the children. Family 2 much preferred the Storytelling component (hence synchronous forms of communication over asynchronous) because it allowed them to speak directly to each other and engage in shared activities such as storytelling, facilitating intense contact with each other. The opposite was the case with Family 2, who preferred the Collage component (primarily asynchronous forms of contact) because it allowed them to easily follow the life of the residents in the other household in an impulsive manner, without having to put too much effort into the interaction or coordination.

Synchronous contact offers immediate advantages over asynchronous forms of contact. One is the possibility to allow the participants to speak to each other in real time. This provides the opportunity for trust to develop or increase between the child and the adult relative (Bos et al., 2002). It also allows both parties to know if, and how much, the other party is paying attention to their conversation. The use patterns of Family 1 illustrate that synchronous contact can be cumbersome to conduct in a time zone distributed family, when both households have daytime responsibilities (work for parents, school for children) that cannot be re-scheduled. Events with a uniform rate of recurrence might thus permanently prevent a family from finding an appropriate time slot for synchronous communication. Synchronous contact does however become easier to conduct when one partner is not constrained by such day time responsibilities, as was the case with the grandmother in Family 2, who was retired and thus had a much more flexible schedule. Even with only two families participating in this study, it is clear that families have different prerequisites for engaging in contact between children and adult relatives across time zones. Technology can thus not solely rely on either synchronous or asynchronous interaction forms, but must incorporate elements of both to accommodate for varying conditions in different families.
Respecting Private and Public time

Zerubavel (1985) suggests that the social accessibility of an individual at any given time can be defined based on two hypothetic maxima, Private Time and Public Time. When an individual is in private time, s/he is not interested in engaging in contact with other people, whereas if the individual is in public time, contact with other people is either sought or encouraged. Even though "neither of them exists in pure form in actuality" (Zerubavel), they still provide the foundation for an interesting consequence for design to be derived from this study. Family 1 allowed the system to play a continuous role in their daily lives, whereas the grandmother in Family 2 used the system less often, but more intensely. The use pattern of the grandmother in Family 2 illustrates how she observed a rather strict distinction between private and public time. When she was home, she turned on the system to indicate that she was ready for communication, but only when she had completed her morning routine. Whenever she left the house, or had visitors, she would turn off the system to indicate private time, at least towards her remote family. Even though Family 1 had their system turned on almost continuously, the patterns observed from the use of the system by the grandmother in Family 2 reveals that appropriate care must be paid to families who wish to observe a more strict division between public and private time. The families had the possibility to do that with the deployed system as the families could turn it off and on at will, suggesting that this is an important property for technology designed for the domestic domain. This is supported by the father from Family 2 who said that regarding the availability indicator implemented as a modification, if it was to be a permanent solution, "I would think you should have a button saying: Yes, I would like to be disturbed right now, if anybody wants to talk to me".

\section{CONCLUSION AND FUTURE WORK}

This paper has explored the important issue of the role of technologies for supporting communication between young children and their grandparents across time zones. A system was deployed and studied in two families, each of which had grandparents living in Denmark and grandchildren living in Australia. By analysing interviews with the families and logged usage patterns, we derived the following understandings that can be used to inform the design technology for this context. We found the following unique problems in communication and maintaining relationships across time zones:

- The two households have misaligned daily routines. There are two main implications of this. Firstly, it is difficult to find a mutual time for the grandchildren and grandparents to communicate. The consequence of this is that parents are needed to negotiate the next meeting time with the grandparents to account for the time difference. Secondly, when talking together the two parties sometimes miss the shared conversational context of the current state of their day. The time indicator showing day and night in the other household solved the need for some of this 
negotiation, and gave a contextual talking point about where the others where in their day.

- Children have activity patterns related to circadian rhythms that don't necessarily fit with the grandparent's rhythm, and hence desire to respond. This is partly solved by the availability indicator, which meant children understood that their grandparents were available to play or read a story "now", and children could then decide if that suited them.

- Children's daily rhythms might more closely match distant grandparents than their parents. Children generally go to sleep earlier than, and rise before, their parents. This might be a time when the grandparents are able and keen to communicate, so the child needs to be able to use the system, and initiate adhoc interactions without the help of a parent. The simple interaction design of the system using touch screens, continual mirroring of content across both sites and a single button to launch the storytelling made this possible.

We understand that these findings on the "stubbornness" of the time zone problem presented are not exhaustive, due to our small sample. As future work, we would like to confront this issue in a more theoretical and philosophical way by expanding this study to include more families using modified technology probes to understand more deeply what it is that makes consistent cross-time zone communication difficult, if not impossible.

\section{ACKNOWLEDGMENTS}

The authors would like to thank the two extended families, in Denmark and Australia, for their participation in the study.

\section{REFERENCES}

Ames, M. G., Go, J., Kaye, J., and Spasojevic, M. Making love in the network closet: the benefits and work of family videochat. Proc. CSCW '10, ACM Press (2010), 145-154.

Ballagas, R., Kaye, J., Ames, M., Go, J., and Raffle, H. Family communication: phone conversations with children. Proc. IDC '09, ACM Press (2009), 321-324.

Bos, N., Olson, J., Gergle, D., Olsen, G., and Wright, Z. Effects of four computer-mediated communications channels on trust development. Proc. CHI '02, ACM Press (2002), 135-140.

CamStudio. http://www.camstudio.org.

Cao, X., Sellen, A., Brush, A. B., Kirk, D., Edge, D., and Ding, $\mathrm{X}$. Understanding family communication across time zones. Proc. CSCW '10, ACM Press (2010), 155158.

Evjemo, B., Svendsen, G. B., Rinde, E., and Johnsen, J. K. Supporting the distributed family: the need for a conversational context. Proc. NordiCHI '04, ACM Press (2004), 309-312.

Friedman, W. J. and Laycock, F. Children's Analog and Digital Clock Knowledge. Child Development, 60, 2 (1989), 357-371.
Hudson, S.E. and Smith, I. Techniques for addressing fundamental privacy and disruption tradeoffs in awareness support systems. Proc. CSCW '96, ACM Press (1996), 248-247.

Hutchinson, H., Mackay, W., Westerlund, B., Bederson, B. B., Druin, A., Plaisant, C., Beaudouin-Lafon, M., Conversy, S., Evans, H., Hansen, H., Roussel, N., and Eiderbäck, B. Technology probes: inspiring design for and with families. Proc. CHI '03, ACM Press (2003), $17-24$.

Kim, S., Kientz, J. A., Patel, S. N., and Abowd, G. D. Are you sleeping?: sharing portrayed sleeping status within a social network. Proc. CSCW '08, ACM Press (2008), 619-628.

Kraut, R. E., Gergle, D., and Fussell, S. R. The use of visual information in shared visual spaces: informing the development of virtual co-presence. Proc. CSCW '02, ACM Press (2002), 31-40.

Lottridge, D., Masson, N., and Mackay, W. Sharing empty moments: design for remote couples. Proc. CHI '09, ACM Press (2009), 2329-2338.

Modlitba, P. L. and Schmandt, C. Globetoddler: designing for remote interaction between preschoolers and their traveling parents. Ext. Abstracts CHI '08. ACM Press (2008), 3057-3062.

Reddy, M. and Dourish, P. A finger on the pulse: temporal rhythms and information seeking in medical work. Proc CSCW '02, ACM Press (2002), 344-353.

Rode, J. A. Digital parenting: designing children's safety. Proc. British Computer Society Conference on Human-Computer Interaction (2002), 244-251.

Stefik, M., Bobrow, D. G., Foster, G., Lanning, S., and Tatar, D. WYSIWIS revised: early experiences with multiuser interfaces. ACM Trans. Inf. Syst. 5, 2 (1987), 147-167.

Strauss A, Corbin J. Basics of Qualitative Research: Grounded Theory Procedures and Techniques. Sage, 1990.

TeamViewer. http://www.teamviewer.com.

Tee, K., Brush, A. B., and Inkpen, K. M. Exploring communication and sharing between extended families. Int. J. Human-Computer Studies 67, 2 (2009), 128-138.

Vetere, F., Davis, H., Gibbs, M., and Howard, S. The Magic Box and Collage: Responding to the challenge of distributed intergenerational play. Int. J. HumanComputer Studies 67, 2 (2009), 165-178.

Vutborg R., Kjeldskov J., Vetere F., and Pedell S. Family Storytelling for Grandparents and Grandchildren living apart. Proc. NordiCHI 2010, ACM Press (2010), 531-540.

Zerubavel, E. The Standardization of Time: A Sociohistorical Perspective. The American Journal of Sociology 88, 1 (1982), 1-23.

Zerubavel, E. Hidden Rhythms. Schedules and Calendars in Social Life. University of California Press, 1985 